\title{
The Influence of Integrated Reporting on Management Control Systems: A Case Study
}

\author{
Maria Serena Chiucchi ${ }^{1}$, Marco Montemari ${ }^{1} \&$ Marco Gatti $^{1}$ \\ ${ }^{1}$ Department of Management, Università Politecnica delle Marche, Ancona, Italy \\ Correspondence: Marco Montemari, Department of Management, Università Politecnica delle Marche, Piazzale \\ Martelli 8, 60121 Ancona, Italy. E-mail: m.montemari@univpm.it
}

Received: March 30, 2018

doi:10.5539/ijbm.v13n7p19
Accepted: April 30, $2018 \quad$ Online Published: June 15, 2018

URL: https://doi.org/10.5539/ijbm.v13n7p19

\begin{abstract}
The purpose of this paper is to investigate how Integrated Reporting can influence Management Control Systems (MCSs). To this aim, the paper presents a case study of a company which designed and implemented an Integrated Report (IR) that was used as a tool for communicating the company performance to the entrepreneur and as a tool for enriching the company MCS to visualize and measure the overall company performance. The case analysis shows that Integrated Reporting improves the measurement focus of the MCS thanks to the role played by the company's Business Model (BM) throughout the IR development and to the process adopted to map the BM itself. The BM mapping process was highly iterative and allowed for a better understanding of the items affecting the value creation process and of their interconnections, thus directing the MCS to what really deserved to be measured. Strategic discussion around the BM also entailed an evolution of the control system, which became a strategic control system, able to support the discussion and the creation of new strategies. Moreover, the BM ensured a high level of integration and consistency between departmental reports and the company IR, on the one hand, and among the departmental reports themselves, on the other hand. In addition, the case analysis shows that financial indicators risk becoming "phagocytized" by non-financial ones and that the implementation process of the IR can lead to a heavier workload for the Management Control Department to provide for the non-financial aspects of performance. Finally, the case analysis shows that the Integrated Reporting visual representation and its underlying logic may not work if the tool is used for managerial decision making. While the guiding principles of Integrated Reporting were accepted by the company's actors, the Integrated Reporting representation model based on the logic inputs-BM-outputs-outcomes was criticized as it was considered too complex and not able to represent the company's integrated performance, reflecting instead a series of disconnected and disjointed individual performances. The critiques of this model were so sharp that they resulted in a change to its logic and the adoption of a different model, namely that of cause-and-effect relationships.
\end{abstract}

Keywords: integrated reporting, management control systems, business model, measurement, key performance indicators

\section{Introduction}

Integrated Reporting has recently caught the attention of scholars (Eccles \& Kiron, 2012; de Villiers et al., 2014; Higgins et al., 2014; Dumay et al., 2016) as well as practitioners, consulting firms, and auditors (KPMG, 2012; EY, 2014; PWC, 2015). In contrast with previous approaches to corporate disclosure, Integrated Reporting leverages on integrated thinking to identify the sources of value creation and their interconnections, thus helping avoid the risk of information being accounted for in separate "chunks" and in numerous, disconnected, and static communications (Adams \& Simnett, 2011, p. 294; IIRC, 2013, p. 2).

Despite Integrated Reporting being initially developed for external purposes, some scholars have recently begun to focus on the potential of this tool to support the managerial decision-making process, i.e., on its effects on decision processes, on managerial practices, and on information provision (Abeseykera, 2013; Adams, 2015; Montemari \& Chiucchi, 2018).

As far as the internal perspective of Integrated Reporting is concerned, there have been recent calls to investigate if and how implementing an Integrated Report (IR) can influence the governance of the company as a whole (Dumay \& Dai, 2014; Dumay et al., 2016). In particular, research streams that deserve additional attention 
concern how the adoption of Integrated Reporting influences Management Control Systems (MCSs) (de Villiers et al., 2016; Perego et al., 2016) and how Integrated Reporting processes are embedded in companies' MCSs (de Villiers et al., 2014). Therefore, this paper aims to contribute to filling this research gap by investigating the following research question: how can Integrated Reporting influence MCSs?

To answer this research question, the authors present a case study of a company that designed and implemented an IR, using the IIRC guidelines, which was used as a tool for communicating the company performance to the entrepreneur and as a tool for enriching the company MCS to visualize and measure the overall company performance.

The paper contributes to the literature on the internal dimension of Integrated Reporting by showing a number of impacts on a company's MCS. The authors maintain that developing an IR improves the understanding of the value creation process and, in turn, the focus of the measurement system, thus confirming Stubbs and Higgins (2014, p. 1085), Burke and Clark (2016, p. 276) and Mio et al. (2016, pp. 215-216). The paper also shows how this can happen; the improvement of the measurement focus can be traced back to the role played by the Business Model (BM) throughout the IR development as well as to the process adopted to map the BM itself. In the case study, the mapping process was highly iterative and this favored the debate among the company's actors and stimulated their strategic thinking on the drivers of value creation.

The BM gradually became the center of the measurement system by providing the logic through which the value creation was mapped and measured within the company. This BM-centered measurement system allowed for a better understanding of the items affecting the value creation process and of their interconnections, and this, in turn, meant directing MCSs to what really deserved to be measured. In addition, the BM also played another role within the company's MCS; it ensured a high level of integration and consistency between departmental reports and the company IR, on the one hand, and among the departmental reports themselves, on the other hand.

In addition, similarly to Beck et al. (2017, p. 11) and Mio et al. (2016, p. 215), the authors acknowledge that the adoption of the IR can foster the use of non-financial indicators. In this paper, the authors also found that financial indicators risked becoming "phagocytized" by non-financial ones, meaning that, as the company IR was being developed, the non-financial Key Performance Indicators (KPIs) gradually caught the attention of the company's actors, while, in their eyes, the financial KPIs seemed to lose importance.

The paper also shows that the design and the implementation process of the IR can lead to a heavier workload for the MC Department, thus confirming what Hampton (2012, pp. 22-24) and Steyn (2014, p. 485) acknowledge regarding the need for companies to change their reporting structures to provide for the non-financial aspects of performance.

Moreover, the case analysis also shows that the Integrated Reporting visual representation and its underlying logic may not work if the tool is used for managerial decision making. While the guiding principles of Integrated Reporting were accepted and embraced by the company's actors, the Integrated Reporting representation model based on the logic inputs-BM-outputs-outcomes was criticized as it was considered too complex and not able to represent the company's integrated performance, reflecting instead a series of disconnected and disjointed individual performances. The critiques of this model were so sharp that they resulted in a change to its logic and the adoption of a different model, namely that of cause-and-effect relationships.

The structure of the remainder of the paper is as follows: Section 2 presents the literature review and the research question, and Section 3 describes the method chosen to answer the research question. Section 4 illustrates the case study and focusses on the process followed to develop the IR within the case company. Finally, Section 5 discusses the case findings and concludes the paper by presenting its main contributions.

\section{Literature Review}

Integrated Reporting is a new approach to corporate reporting which aims to represent how an organization creates and sustains value, by integrating financial and non-financial information in a clear, concise, consistent, and comparable format (IIRC, 2013, p. 2). In contrast with previous approaches to social and environmental disclosure, where non-financial information was barely integrated with financial information (de Villiers et al., 2014), Integrated Reporting leverages integrated thinking to identify the sources of value creation and their interconnections, thus helping avoid the risk of information being accounted for in separate "chunks" and in numerous, disconnected, and static communications (Adams \& Simnett, 2011, p. 294; IIRC, 2013, p. 2).

According to the IIRC website, more than 1,000 organizations are publishing an IR and the Integrated Reporting agenda has attracted the interest of a growing number of scholars (Eccles \& Kiron, 2012; de Villiers et al., 2014; Higgins et al., 2014; Dumay et al., 2016) as well as consulting firms and auditors (KPMG, 2012; EY, 2014; PWC, 
2015).

A number of published studies have primarily examined, through both theoretical and empirical contributions, the type and level of disclosure in company IRs (Frostenson et al., 2012; Fifka, 2013). The studies to date have focused on the benefits of Integrated Reporting from an external disclosure perspective for stakeholders, compared to traditional and sustainability reporting. In particular, it has been argued that Integrated Reporting helps provide forward-looking information (Adams \& Simnett, 2011; Watson, 2011); it may clarify how organizations create and sustain value (Hampton, 2012; Watson, 2011); it can provide a more concise, holistic, and balanced picture of organizational performance (Eccles \& Krzus, 2010); it may improve transparency, governance, and decision making for organizations of all types (Adams et al. 2011; Hampton, 2012); it helps put the social, environmental, and governance issues at the core of the organization's value creation strategy (Eccles \& Kiron, 2012), and, finally, it may enhance the disclosure of intangible dimensions of companies, overall intellectual capital, and human capital (Haji \& Anifowose, 2017).

Research has also shed light on the critical aspects of designing and implementing an IR. In particular, it has been argued that disclosure on interdependencies and trade-offs among capitals and components of capitals is often scarce (Haji \& Anifowose, 2017); moreover, central concepts for designing and implementing an IR, like integrated thinking, are not clearly defined by IIRC and there is no consensus on their meanings among IR developers and stakeholders, thus making the IR confusing and difficult to implement (Feng et al., 2017).

While academic research has directed its attention predominantly towards the strengths and weaknesses of Integrated Reporting from an external disclosure perspective, some scholars have recently begun to focus on the internal dimension of Integrated Reporting, i.e., the organizational effects of the design and implementation of an IR, thus highlighting its effects on decision processes, on managerial practices, and on information provision (Abeseykera, 2013; Adams, 2015; Montemari \& Chiucchi, 2018).

As de Villiers et al. (2016) argue "there is much to learn and understand, especially around the internal processes and systems needed to measure and manage relevant information for Integrated Reporting".

Following along these lines, there are some aspects that require, and deserve, additional attention, namely why companies decide to start an Integrated Reporting journey, what approaches and internal mechanisms companies use to design and implement an IR, what the challenges to be faced are, how and why successful (or unsuccessful) experiences occur, and what the levers and the barriers to the adoption of Integrated Reporting in practice are (Dumay et al., 2016).

The growing attention on the internal dimension of Integrated Reporting has led some authors to focus on the relationship between MCSs and Integrated Reporting, focusing on the effects of the IR design and implementation on MCSs. Despite the IR having been initially developed for external purposes, awareness of the potential of this tool to support the managerial decision-making process is on the rise. Pivoting on the integrated thinking, Integrated Reporting is considered able to show the connections between the financial and the non-financial information (Abeysekera, 2013; Van Bommel, 2014; Thomson, 2015), thus helping enhance a holistic view of company performance and to favor the understanding of the effects of managerial actions in the short, medium, and long run (Stubbs \& Higgins, 2014; Adams, 2015).

Moreover, research has highlighted that Integrated Reporting can improve MCSs in terms of increased alignment with strategy: following the Integrated Reporting guiding principles can help develop measures that are in keeping with the company's strategic directions (Montemari \& Chiucchi, 2018), and better capture (and report) the company's ability to create value over the short, medium, and long term (Lodhia, 2015, p. 593; Mio et al., 2016, p. 206). Thus, Integrated Reporting may improve the measurement focus of MCSs in that it may favor a better understanding of the items affecting the value creation process and of their interconnections (through the company's business model), and this, in turn, means directing MCSs to what really deserves to be measured (Stubbs \& Higgins, 2014, p. 1085; Burke \& Clark, 2016, p. 276; Mio et al., 2016, pp. 215-216).

In addition, research has acknowledged that the intangible nature of certain Integrated Reporting capitals (social, human, and intellectual) can lead to the implementation of non-financial measures and this promotes a multidimensional and balanced measurement of performance in MCSs (Mio et al., 2016, p. 215; Beck et al., 2017, p. 11; Montemari \& Chiucchi, 2018).

Finally, Integrated Reporting implementation challenges have also been recognized by prior research; Integrated Reporting requires new methodologies to collect and to process information needed to provide measures for non-financial aspects of performance; in turn, this often entails a reconfiguration of reporting structures and subsequent costly and time-consuming adjustments to MCSs (e.g. investments in new IT systems) (Hampton, 
2012, p. 22; Steyn, 2014, p. 485).

Recently, there have been calls to investigate if and how implementing Integrated Reporting can influence MCSs and, more broadly, the governance of the company as a whole (Dumay \& Dai, 2014; Dumay et al., 2016). In particular, research streams that merit additional attention concern how the adoption of an IR influences MCSs (de Villiers et al., 2016; Perego et al., 2016) and how Integrated Reporting processes are embedded in companies' MCSs (de Villiers et al., 2014).

In light of this research gap, this paper aims to investigating the following research question: how can Integrated Reporting influence MCSs?

\section{Method}

In order to answer the research question, the authors present a single, in-depth case study referred to Nexus, an Italian company which decided to design and implement an IR for internal purposes.

The case study method was chosen to achieve the research objective because it allows for a holistic and in-depth analysis of a complex phenomenon in its real-life context (Yin, 2003), namely exploring and analyzing the design and the implementation of an IR, gaining a clear view of the interplay between Integrated Reporting and MCSs and focusing on the interactions among company actors while designing and implementing an IR. Accordingly, the case was chosen purposefully (Patton, 1990) because it allowed the researchers to gain rich information about the issues of central importance to the purpose of the research. In the present paper the authors reflect on the reasons that led to choosing the IR, on the process developed to design and implement the IR, on the needed adaptations to the IR, on the challenges faced during internal implementation, and on the levers and barriers encountered during the design and implementation process of the IR. One of the two authors had the opportunity to participate as an "expert" in some meetings geared toward discussing the design and implementation of the IR.

Data was gathered through document analysis (internal reports and presentations), interviews, and participant observations conducted during meetings among the company actors involved in the project, i.e., the President of the Group, the General Manager, the Group controller, a PhD student who was cooperating with the controller in developing the IR, and top management (the R\&D manager, the Market Development manager, the Communications manager, the Human Resources manager). All interviews and meetings were recorded and transcribed in full, with the permission of the company. Using several methods to collect data was useful to cross-validate the information gathered and to capture different facets of the phenomena under analysis (Ryan et al., 2002).

Semi-structured interviews were carried out with the company actors who actively participated in the design and the implementation of the IR, in gathering data, and in calculating the indicators, specifically, the General Manager, the Group controller, the PhD student who contributed to developing the IR, and the top managers. The semi-structured interview was chosen as a data collection method because themes that come to light during the interview can be addressed immediately; the flexibility of this method enhances the understanding of the motivations that drive the interviewee's actions as well as his/her interpretation of the reality (Kvale and Brinkmann, 2009). The interviews were aimed at understanding how Integrated Reporting was implemented internally, the levers and the barriers encountered during the implementation, as well as if and how Integrated Reporting influenced the MCS. Reflexive questions were extensively used during the interviews, as suggested by Kreiner and Mouritsen (2005). Asking for examples, stories and/or anecdotes encourages the interviewees to provide detailed information and triggers, in turn, other stories and thoughts on the phenomena under investigation. Moreover, one of the two co-authors attended the meetings among the company actors involved in the project.

Qualitative data analysis was applied to the interview, documental, and observational data as this made it possible to focus on what respondents thought, felt, or did when it came to designing and implementing the IR; it also helped maintain sensitivity to the context (Denzin \& Lincoln, 2000; Patton, 2002). Some of the company actors' verbatim quotes are provided throughout the paper (in italics and quotation marks) to support reflections and findings.

\section{The Case Study}

Section 4 illustrates the case study and focuses on the process followed to develop the company IR. In particular, Section 4.1 introduces the case company and underlines the information needs that led to developing the IR. Section 4.2 describes how the Group's BM was mapped, while Section 4.3 follows the development of the departmental report for the R\&D Department by highlighting how the contribution of this business Department 
to the Group's BM was identified and how KPIs were established. Finally, Section 4.4 describes the process that led to the design of the company IR.

\subsection{The Case Company}

Nexus is the holding company of a Group whose core business is the design and production of turnkey tailor-made solutions for the automatic measurement and quality control of customers' products and processes. The Group's headquarters are located in Italy, but its solutions are sold worldwide.

Nexus develops and provides services related to human resources, research and innovation, administration and control, marketing and business development to all Group companies. The mission of Nexus is to imagine and plan the future of the Group through its intangible resources, activities, and outcomes. Four business Departments operate within Nexus: 1) Research and Development (R\&D) aims to develop incremental and radical innovation to enhance the know-how and the technologies of the Group; 2) Market Development searches for new market opportunities and new customers; 3 ) Communications spreads the company culture and image inside and outside the Group with the aim to strengthen the company values; 4) Human Resources recruits, trains, and evaluates the human resources of the Group.

When the project was launched, financial performance was at the core of Nexus' Management Accounting (MA) system which was centered on financial KPIs, a cost accounting system, variance analysis. The MA system did not provide information on the non-financial dimensions of company performance, meaning that a relevant share of the company's performance remained hidden; Nexus' activities yield indeed several intangible outcomes (new competences, new customer relationships, new technological solutions) whose size, growth, decline, and impact on the Group value creation process was not revealed by the MA system.

Given this flaw of the MA system, the top management information needs were twofold: on the one hand, the management felt the need to convey to the entrepreneur a complete overview of the results achieved by Nexus and, on the other, to have a tool within the MCS able to define the objectives to be achieved, to guide the managerial actions, and to report on the results achieved. During the time period that is being focused on in this paper, the company did not have such a structured tool within its MCS. In order to improve the MA system and satisfy both of the management needs, the decision was made to design an IR according to the IIRC framework.

Already from the outset of the project, it immediately became clear that a strong integrated thinking distinguished Nexus. Integrated thinking takes place when there is constant interplay between financial and non-financial dimensions of the business; when all operating and functional units break down internal barriers and work together to achieve the company's strategic objectives; when decision-making and actions consider the creation of value not only over the short term, but also over the medium and long term (IIRC, 2013). At Nexus, non-financial considerations were usually incorporated in the decision-making process in order to realize benefits in the long run, thus going beyond the short term financial dimension. For instance, an extensive range of partners (universities, research centers, customers, and suppliers) collaborates with the company to develop EU projects. Beyond the main aim of acquiring funding, these EU projects are also considered an opportunity to interact and collaborate with leading actors in specific industries in order to build new competences and extend the network of technological partners in the medium and long run. Moreover, internal barriers among the company's business Departments are very thin; their competences, activities, and operations are integrated in order to nurture and manage the different facets of the relationships with customers and all stakeholders in an effort to achieve benefits also in the medium and long term.

Consistently with the integrated thinking which characterizes Nexus, an IR was developed, according to the IIRC framework, that aimed at identifying and measuring the tangible and the intangible resources and activities developed to create value and the resulting tangible and intangible outputs and outcomes.

During the project, the business Departments expressed a specific information need, i.e., to each have its own report to support the decision-making process in a manner consistent with the company's business strategy. Therefore, besides the preparation of the company IR addressed to the entrepreneur and to top management, departmental reports were also created during the project. The company BM acted as the pivot point for the design of the departmental reports and the company IR to ensure a high level of consistency in the whole system of reports.

\subsection{Identifying the Group's BM}

Consistently with the IIRC framework (IIRC, 2013, p. 5), the first step of the process regarded the identification of the Group's BM. The BM is the framework used by companies to implement their strategy (McGrath, 2010; Nielsen \& Montemari, 2012); its identification helps understand how value is actually created and captured 
(Osterwalder \& Pigneur, 2010; Arend, 2013). During one of the meetings, the controller highlighted how the identification of the BM was crucial to the success of the measurement process:

"If there is something wrong in the BM mapping, we will identify KPIs which are not consistent with the value creation process, and are useless for the decision-making process. [...]. BM mapping helps us keep track of the reasons why we choose some KPIs and discard other ones".

It is worth of note that the BM mapping was a highly iterative process; several meetings and interviews with the company's actors were needed to grasp the real essence of the Group's BM. Moreover, the company' actors were also trained on the BM concept and gradually gained the competences needed to contribute to its mapping process. Thus, this step of the process was highly intensive and challenging for the company's actors, who were also aware that this step was crucial to the success of the following ones.

From a technical point of view, the company's BM was identified using a portfolio of BM configurations, thus following the process suggested by Gassmann et al. (2014) and Taran et al. (2016). A BM configuration is a precise recipe for doing business that describes how the company creates, delivers, and captures value (Baden-Fuller \& Morgan, 2010). Sometimes the naming of the specific BM configuration is done through the example of a well-known company, such as the eBay BM, the Dell BM, the Ryanair BM, the Gillette BM and the Skype BM.

In line with the assumption that every real-life company is a combination of different BM configurations (Taran et al., 2016), the mapping process led to the following mix of BM configurations: solution provider, open BM, systems integrator, layer player, outside-in (see, Table 1).

Table 1. The Group's BM configurations and their key features

\begin{tabular}{|c|c|}
\hline BM configuration & Key features \\
\hline Solution provider & $\begin{array}{l}\text { Solution provider aims to provide a total and complete coverage of products and services in one particular } \\
\text { area of expertise (e.g. financial, health) in order to offer the customers an all-inclusive package (product } \\
\text { sales, installation, consulting services, after-sales services, spare parts, and maintenance) able to satisfy a } \\
\text { wide range of needs in a particular domain. }\end{array}$ \\
\hline Open BM & $\begin{array}{l}\text { Open BM aims to create an "ecosystem" by establishing its technologies as the basis for value chain } \\
\text { innovation. The ecosystem develops around the focal firm's technologies whose disappearance would } \\
\text { destroy the whole ecosystem. }\end{array}$ \\
\hline Systems integrator & $\begin{array}{l}\text { Similarly to solution provider, systems integrator offers an all-inclusive package of highly customized } \\
\text { products and services. However, the focus here is on the ability to coordinate and integrate internal and } \\
\text { external sources of tangible and intangible components in order to develop novel combinations of solutions } \\
\text { for customers. }\end{array}$ \\
\hline Layer player & $\begin{array}{l}\text { Layer player focuses on a specific function in the value chain, such as electronic payments or logistics, } \\
\text { with the intent to serve a number of different value chains in several industries. Indeed, specific } \\
\text { competences on a core area of expertise can be used as a platform to serve several industries. }\end{array}$ \\
\hline Outside-in & $\begin{array}{l}\text { Outside-in obtains } \mathrm{R} \& \mathrm{D} \text { from external entities and builds on it in order to shorten time-to-market and } \\
\text { increase internal } \mathrm{R} \& \mathrm{D} \text { productivity. Moreover, this } \mathrm{BM} \text { configuration exploits external sources of } \\
\text { technology and knowledge to complement the internal ones in order to be able to serve broader markets. }\end{array}$ \\
\hline
\end{tabular}

This BM mapping process also led to the identification of some strategic themes closely linked to the mix of BM configurations and considered crucial for the value creation process of the Group. Table 2 shows the outcome of this matching process between BM configurations and strategic themes:

Table 2. The Group's BM configurations and the related strategic themes

\begin{tabular}{ll}
\hline BM configurations & Group's strategic themes \\
\hline Open business model; systems integrator & Aptitude for collaboration \\
Open business model; systems integrator & Ability to create new knowledge \\
Open business model; outside-in & Ability to acquire new knowledge \\
Systems integrator; solution provider & Ability to develop ad-hoc solutions for customers \\
Open business model; layer player & Ability to diversify \\
\hline
\end{tabular}




\subsection{Developing the Departmental Reports}

The Group's BM and the strategic themes were used as a guide to identify how the resources, activities, and outcomes of the business Departments affected these strategic themes, thus contributing to the value creation process of the Group as a whole. This step was a prerequisite to building both the departmental reports and the company IR. This section will follow the development of the report for the R\&D Department, which most strongly felt this need.

The departmental measurement system of the R\&D Department was focused on R\&D project timeliness and expenses and, as a consequence, it was not able to reveal the intellectual and technological outputs of this Department. The R\&D Department was searching for other kinds of numbers able to physically show the "returns on investments" of the research activity and its real contribution to the value creation process of the Group.

The Integrated Reporting project, then, provided the opportunity to have a departmental report that included information on the intellectual and technological outputs resulting from the research activity. To develop the report, R\&D personnel reflected on how the resources, activities, and outcomes of the R\&D Department influence the Group's BM and strategic themes. For example, the R\&D Department strongly supports the achievement of "Aptitude for collaboration" and "Ability to acquire new knowledge" by collaborating with a wide range of external partners (universities, research centers, customers, and suppliers) not only to carry out EU projects, but also to develop new competences. This Department also supports the achievement of the "Ability to develop ad-hoc solutions for customers": new technologies acquired from external parties are integrated with internal know-how so that tailored solutions for customers can be created. Also "Ability to diversify" is influenced by R\&D: once internal and external knowledge are integrated, the R\&D Department converts this integrated knowledge to enable its use in as many industries as possible.

The design of the KPIs was guided by these reflections, meaning that the measures were chosen according to the contribution made by the R\&D Department to the BM of the Group. As the R\&D Department is so intangible-intensive, KPIs are predominantly non-financial and are related to intangible dimensions of performance. For instance, four KPIs were designed in order to measure the "Aptitude for collaboration", namely "Number of European and national projects", "Number of conference attendances", "Number of non-disclosure agreements", "Number of hosted partners". These KPIs are designed to keep track of the ability of the Department to create an extended network of partners with whom to cooperate.

Moreover, as the R\&D Department creates "tailor-made" solutions for customers, the development of close and intensive contacts with clients is an aspect worth monitoring. For this purpose, the KPIs "Number of visits to customers" and "Number of feasibility studies for customers' specific needs" were inserted in the report. This bundle of non-financial KPIs is calculated quarterly and is included in a departmental report, along with preexisting financial measures.

All in all, the new departmental report goes beyond the measurement of the short-term financial results and provides a complete overview of the R\&D Department's contribution to the value creation process of the Group by introducing forward-looking KPIs related to the non-financial dimensions of performance.

This process was repeated for the remaining business Departments in Nexus, so that each Department could have a departmental dashboard of its KPIs strictly linked to the value creation process of the Group. It is worth noting that the design and the calculation process of the KPIs was an onerous and time-consuming task. Several brand new KPIs were designed; therefore, they had to be calculated from scratch and most of them were non-financial measures, meaning that the information needed was mainly qualitative in nature and had to be collected through interviews and face-to-face interactions with the company's managers and employees.

\subsection{Designing the Company IR}

The last step of the process concerned the design of the company IR. For this purpose, the Integrated Reporting framework based on capitals and on the model inputs-BM-outputs-outcomes was presented to the company actors during a meeting. At the outset of the project, the IR to be adopted had already been illustrated and, at that time, the presentation went smoothly and no objections or opposing viewpoints were expressed by the managers. During this presentation, some criticalities arose. First, the word "capital" was rejected by the company actors as it was considered too static and not consistent with the company's language. In this case, the issue was merely related to the Integrated Reporting language, seeing as the concept underlying the word "capital", i.e., dimension of performance, was instead accepted and used to verify that all the material aspects of performance were properly measured. 
Second, and more important than the terminology issue, the Integrated Reporting model based on inputs-BM-outputs-outcomes was perceived by managers to be too complicated and not effective to represent the company's integrated performance. The Integrated Reporting framework based on capitals and on the logic input-BM-output was not deemed suitable to understand how the company resources were related to and interacted with each other; thus, it was not considered able to provide a concise and integrated picture of the company's performance. During one meeting, the controller highlighted that the Integrated Reporting capitals did not adequately fit the purpose of the report by stating:

"Categorizing KPIs within the Integrated Reporting capitals is not adding anything of substance to the report. We would end up with a 'sum' of KPIs, while we would need, instead, a system of linked KPIs".

The CEO highlighted this weak point of the Integrated Reporting model from his point of view:

"In this report, I would like to see the 'summary' of the 'summary' of the performance; something which can express, at the end of the day, where is the company going? [...]. Taking the customers as a frame of reference, where do I see the process that leads from the first contact to the feasibility study, to the first offer, and finally to the revenue generation? We need an integrated view of our performance".

In the CEO's mind, therefore, an IR should clearly visualize and measure the linkages among actions and area (in his words "the process") and should also express the integrated performance in a concise way (again, in his words “the 'summary' of the 'summary"'). The search was on for a number - or very few numbers - which could represent the company's performance.

After several discussions during the focus groups, the company's actors chose a different way of visualizing the company's integrated performance, i.e., that of cause-and-effect relationships. During one meeting, the CEO triggered this idea by asking the controller:

"Try to give a logical sequence to the KPIs. Take for example the KPIs concerning the strategic theme 'People initiatives/Liveliness', I would put the 'Number of Nursery Squad Projects' at the beginning of the sequence, then 'Training' and 'Projects for collaborators', and finally 'Company Turnover' and 'Company Climate,",

Following along these lines, the controller stated:

"So, here the challenge is to link the KPIs with each other, we could then understand the causes and the effects in the relevant dimensions of performance".

The choice of the model based on cause-and-effect relationships guided the selection of the KPIs to include within the company IR. For the sake of efficiency and considering the acquired familiarity with some indicators, the commitment was also to try to re-use some of the KPIs which already existed in the departmental reports.

Thus, a selection of departmental KPIs was inserted in the company IR; this selection was guided by the ability of the chosen KPIs to represent the strategic themes identified in the company BM. As a matter of fact, the achievement of some departmental objectives was also crucial for the value creation of the company as a whole. For example, the KPIs "Number of training hours" and "Number of job rotations" monitor the causes of the strategic theme "People initiatives/Liveliness", while the effects are kept under control through "Company turnover" and "Company climate". All these KPIs were selected from the departmental report of the HR Department. However, brand new KPIs were also developed ad hoc for the company-wide report. The first reason was that, even though the departmental KPIs were referred to the strategic themes, some of them were too specific, i.e., too focused on operational goals, to provide an overall view of how the company was performing on a given strategic theme. For example, when it came to choosing the KPIs for the "Network development", instead of the KPI "Number of new contacts" (already included in the Communications departmental report to measure this strategic theme), in the company IR "Number of new high value contacts" was chosen to provide management with information only on the new contacts which were likely to create strategic advantages for the company. The second reason was that some strategic themes (e.g. territoriality/environment) had not emerged at the departmental level but only at the company level and thus, new measures had to be identified. All in all, the choice of the KPIs was gradually made through several meetings among the company actors; this made this process highly iterative and the discussions that arose around the choice of the KPIs were aimed at improving the relevance and the selectiveness of the company IR.

It is worth of note that, at the outset of the project the MA system was centered mainly on financial KPIs and it was hard to persuade the company actors to accept the fact that in order to measure the company value it was 
necessary to introduce non-financial KPIs, as well. Involving company actors in the design of the IR, thus in the reflections on how the company creates value in the short, medium and long-term, in the design of the BM, in identifying the strategic themes and finally, in establishing the KPIs was useful as it made the actors familiar with non-financial indicators and with a more integrated way of measurement. Unexpectedly, this process risked ending up with the exact opposite effect. Non-financial KPIs gradually caught the attention of the company's actors because they were closer to their activities ("They fit well", as one actor noticed) while financial KPIs seemed to have lost importance in their eyes. Thus, in the end, financial indicators referred to costs or revenues and which could be relevant for monitoring certain aspects of the company performance were somehow neglected. When this was highlighted by one researcher during one particular meeting, financial KPIs were then "reconsidered" and re-introduced into the dashboard.

Although the model based on cause-and-effect relationships was considered more effective than the Integrated Reporting model to visualize the company's integrated performance by the CEO and all the top managers, this choice was neither unanimous nor immediate; it was, at any rate, the result of a compromise among the company's actors. During one meeting, the following dialogue took place:

CEO: "I would leave in the company IR only the KPIs that measure the effects. The report has to provide us a 'summary' of the performance".

Head of Research and Development Department: "I would definitely keep also the KPIs that measure the causes. It usually takes years before we can see the effects of our managerial actions, then years go by and we always forget where the effects come from. We have to keep track of the causes, also". [...]. Then the CEO gave way to the model based the cause-and-effect relationships, but he warned the other company's actors of the complexity of the model itself:

CEO: "This way of representing KPIs is useful, but complex. Each effect has at least 3 or 4 concurrent causes and it will be difficult to identify the main cause out of the 3 or 4. And I still think that this will not be a 'summary'report".

After the illustration of some examples of the cause-and-effect relationships among KPIs, one manager echoed the CEO's thoughts:

Head of the Communications Department: "The cause-and-effect representation works in my opinion. By the way, I have to admit that I still do not understand where the ultimate 'summary' of the performance is".

Despite the critique to the Integrated Reporting representation, a compromise on the cause-and-effect relationship model was reached. During these meetings, the debate that arose on this issue and the KPI selection process triggered discussions on strategy among participants. The company actors discussed the relevant dimensions of Nexus' performance, how they were interconnected, how they were measured by the control system and represented within the company IR. For example, during one meeting, the Communications manager stated:

"One of the main missions of Nexus is to think differently and to create discontinuities within the group. Where and how do we measure discontinuity in this report?".

In response to this question, the $\mathrm{CEO}$ and the other managers highlighted how the different facets of discontinuities were measured through new competences, new business units, new customers, for example.

Following along these lines, discussions on the future of the company were also initiated. For example, the CEO stated:

"We should try to understand where we will be in 10 years' time. How will the company evolve in 10 years' time? We did not have the international branches 10 years ago, but then we created them and they made a huge difference to us. The last 10 years were very intense in terms of organizational change. But who will be the new employees in 10 years'time? And the new managers? And the new branches? We have to keep track of how the company changes over the years, and the reference period has to be 10 years".

This thought triggered a discussion among the company's actors on how to frame this theme within the IR, which aspects to include, and how to measure them. As a result, an additional strategic theme was crafted and added to the IR, namely "Organizational Evolution", and KPIs to monitor it were identified (e.g.: "Number of new international branches", "Number of new joint ventures", "Number of new working positions created").

In sum, this bundle of strategic discussions led the top management of Nexus to enrich and refine the strategic 
themes and thus to refine and innovate the company's BM. Some strategic themes were broadened ("People initiative/Liveliness" was expanded as "People"), some others were merged ("Ad hoc solutions for customer problems" was combined with "New knowledge development/acquisition") and some were added ("Organizational Evolution"). Questions like "What do we mean by this strategic theme?", "What should we include within it?", "How are these strategic themes linked?", "How should we measure it?" were constantly posed during the meetings. This shows that, designing the IR was a process that helped the company's actors make sense of what was really material for the value creation process, in the medium and long term, and to give the strategic theme a shared content and meaning.

\section{Discussion and Conclusions}

The aim of the paper was to investigate how Integrated Reporting can influence MCSs. To answer this question, we presented a case study of a company which designed and implemented an IR, using the IIRC guidelines, to measure its overall performance and to communicate it to the entrepreneur. Therefore, the IR was used as a communication tool and as a tool for enriching the company MCS. Given these aims, the development of the IR was expected to influence the company MCS.

If we consider the entire story, we observe that while the guiding principles were adopted and implemented, the visual representation and its underlying logic were changed. Thus, the IR became part of the company MCS, but it needed some adaptations.

The case analysis shows a number of impacts of Integrated Reporting on the company MCS. Similarly to Stubbs and Higgins (2014, p. 1085), Burke and Clark (2016, p. 276) and Mio et al. (2016, pp. 215-216), we found that Integrated Reporting improves the understanding of the value creation process and, in turn, the focus of the measurement system. Thus, our findings confirm and refine those of previous literature by pointing out how this can happen; the improvement of the measurement focus was due to the process followed to develop the IR and to the role played by the company's BM throughout the IR design and implementation. The process was indeed heavily based on the BM identification; several meetings were organized to map it, and this favored the debate among the company's actors and stimulated their strategic thinking on the drivers of value creation.

This highly iterative process entailed the involvement of Departments which had previously participated in the company's managerial reporting (e.g. Human Resources, Communications) just by indicating only their expenses. Seeing the company's BM as the pivot helped managers not only to show how they contributed to company value creation, but also to become aware of how the other Departments create value. This involvement triggered strategic discussions among managers on what the material aspects of the company's performance truly were and on how to measure them, on the interconnections among managerial actions of the different Departments, on the future strategic challenges of the company "in 10 years' time". Thus, BM mapping also entailed an evolution of the control system, which became a strategic control system, able to support the discussion, the check and the creation of new strategies. Following along these lines, the case analysis shows that the process of mapping the company's BM was able to operationalize integrated thinking, i.e., by showing the constant interplay between the financial and non-financial dimensions of the business; breaking down all operating and functional units' internal barriers to achieve the company's strategic objectives; taking decisions that consider the creation of value not only over the short term, but also over the medium and long term. In so doing, the paper contributes to the call made by Feng et al. (2017) for more research on clarifying what integrated thinking means in practice.

The BM became then the center of the measurement system by providing the logic through which the value creation was mapped and measured within the company. This BM-centered measurement system allowed for a better understanding of the items affecting the value creation process and of their interconnections, and this, in turn, meant directing MCSs toward what actually deserved to be measured. The BM played another role within the company's MCS, also; it ensured a high level of integration and consistency between departmental reports and the company IR, on the one hand, and among the departmental reports themselves, on the other hand. Even though the strategic themes used at a company level to identify KPIs were slightly different from the ones used in each Department, both the company level and the departmental level strategic themes had the same roots consistent with the company's BM.

All in all, the design and implementation of the IR provided the company with a structured measurement method anchored in the value creation logics of the company because it was heavily based on and guided by the company BM. In the words of the company controller:

"What I like about this project is that it leaves us a 'measurement method', a rationale behind the design of KPIs; the real value of this project is not only the KPIs per se, which can be changed in the 
future according to managerial information needs, but the step-by-step process that we followed to design it, in consideration of all the work that we did to map the company's BM".

In addition, similarly to Beck et al. (2017, p. 11) and Mio et al. (2016, p. 215), we acknowledge that the adoption of the IR fostered the use of non-financial indicators. In this paper, the authors also found in the case under analysis that financial indicators risked becoming "phagocytized" by non-financial ones, meaning that the company' MCS would have provided un unbalanced view of the performance, centered predominantly, if not exclusively, on non-financial aspects. This was probably due to a combination of two factors, a company-specific one and an Integrated Reporting-related one. The first one concerns the nature and the features of Nexus' Departments; designing KPIs for intangible-intensive Departments and privileging, in the IR, indicators from the departmental reports may lead to centering the IR predominantly on non-financial aspects of performance. The second one regards the nature of Integrated Reporting capitals; as acknowledged by Mio et al. (2016), the focus on intangible capitals entails the design of a bundle of KPIs focused on the soft aspects of performance, namely non-financial KPIs.

Finally, the case analysis has shown that the design and the implementation process of the IR led to a heavier workload for the Management Control Department. A specific person was in charge of data production, collection and analysis. Just a few KPIs were already available in the company's MCS; several brand new non-financial KPIs were designed and calculated ex novo, mainly through interviews and face-to-face interactions with the company's managers and employees. Thus, this finding confirms what Hampton (2012, pp. 22-24) and Steyn (2014, p. 485) acknowledge regarding the need for companies to change their reporting structures to provide for the non-financial aspects of performance.

The case analysis also shows that while the guiding principles of Integrated Reporting were accepted and embraced by the company's actors, the Integrated Reporting representation model and its logic based on inputs-BM-outputs-outcomes were criticized as they were considered too complex and, most of all, not able to represent the company's integrated performance. To this aim, a cause and effect logic was considered more suitable. We recall that at the outset of the project, no objections or opposing comments were raised by the managers concerning the Integrated Reporting representation model. Subsequently, the highly iterative process that followed to develop the IR allowed the company's actors to form their own idea of what an integrated performance is. This sense making process led the company's actors to question the Integrated Reporting representation model and its underlying logic. In all, our findings highlight that the Integrated Reporting visual representation and its underlying logic may not work if the tool is used for managerial decision making.

Given the promises of Integrated Reporting and its strong focus on the integrated performance, some of the company's actors interpreted "integrated" also as a synonym for concise view of the company performance. In the eyes of some actors, the Integrated Reporting representation model based on capitals reflected instead a series of individual performances, whose connections were not evident. They appeared disconnected and disjointed. Therefore, a different visualization model and a different logic was chosen to better express the integrated performance, namely that of cause-and-effect relationships. Although the model based on cause-and-effect relationships was considered more effective than the "traditional" Integrated Reporting model based on capitals to visualize the company's integrated performance by the CEO and all the top managers, this choice was nevertheless perceived as the result of a fragile compromise among the company's actors.

To sum up, while the guiding principles worked for internal decision-making purposes, the Integrated Reporting representation model and its underlying logic did not. When it came time to take managerial decisions, the critiques to this model were so strong that the logic was changed and the cause-and-effect relationship model was adopted.

From a practical point of view, the paper underlines that BM mapping drives the entire Integrated Reporting journey and a good share of its success or failure. IR developers should be aware that this step is crucial when it comes to actually designing and implementing an IR in companies. Thus, they should be very careful in planning and implementing this step concerning, for example, the choice and the implementation of a BM mapping technique, the company's actors to be involved, and the amount of time allocated to this step.

It is important to also acknowledge the limitations of this paper. Although the use of a single case study provides in-depth and rich data, it also limits the generalizability of the observations to other companies; the findings could have been influenced by the specific process adopted to develop the IR and the specific technique used to map the Group's BM.

This paper followed the design and the implementation of the IR and showed a number of effects on the company MCS, namely the improvement of the measurement focus, the transition to a strategic control system, 
the improved integration between departmental reports and company-wide reports, the risk for the financial KPIs to be phagocytized by non-financial KPIs, and the heavier workload for the Management Control Department.

Moreover, the paper showed that the Integrated Reporting visual representation and its underlying logic may not work if the tool is used for managerial decision making. The need to make explicit the cause-and-effect relationships is an aspect that deserves attention if the tool has to be used within the company MCS. In view of this consideration, follow-up interviews could be carried out to investigate if and how the company IR is used to guide managerial actions or if it has ended up not being used.

Finally, it could be interesting to delve into the role of the BM in the integration between departmental reports and company-wide reports. By focusing on the dynamics among actors, levers and barriers which can arise in this process could be highlighted.

\section{References}

Abeysekera, I. (2013). A template for integrated reporting. Journal of Intellectual Capital, 14(2), 227-245. https://doi.org/10.1108/14691931311323869

Adams, C. A. (2015). The International Integrated Reporting Council: A call to action. Critical Perspectives on Accounting, 27, 23-28. https://doi.org/10.1016/j.cpa.2014.07.001

Adams, S., \& Simnett, R. (2011). Integrated reporting: An opportunity for Australia's not-for-profit sector. Australian Accounting Review, 21(3), 292-301. https://doi.org/10.1111/j.1835-2561.2011.00143.x

Adams, S., Fries, J., \& Simnett, R. (2011). The journey toward integrated reporting. Accountants Digest, 558, $1-41$.

Arend, R. J. (2013). The business model: Present and future - beyond a skeumorph. Strategic Organization, 11(4), 390-402. https://doi.org/10.1177/1476127013499636

Baden-Fuller, C., \& Morgan, M. S. (2010). Business models as models. Long Range Planning, 43(2), 156-71. https://doi.org/10.1016/j.lrp.2010.02.005

Beck, C., Dumay, J., \& Frost, G. (2017). In pursuit of a 'single source of truth': From threatened legitimacy to integrated reporting. Journal of Business Ethics, 141(1), 191-205. https://doi.org/10.1007/s10551-014-2423-1

Burke, J., \& Clark, C. (2016). The business case for integrated reporting: Insights from leading practitioners, regulators, and academics. Business Horizons, 59(3), 273-283. https://doi.org/10.1016/j.bushor.2016.01.001

De Villiers, C., Maroun, W., \& Stent, W. (2016). Integrated Reporting: linkages with organisations' internal processes. Call for paper on Meditari Accountancy Research. Retrieved from http://www.emeraldgrouppublishing.com/products/journals/call_for_papers.htm?id=6858

De Villiers, C., Rinaldi, L., \& Unerman, J. (2014). Integrated Reporting: Insights, gaps and an agenda for future research. Accounting Auditing \& Accountability Journal, 27(7), 1042-1067. https://doi.org/10.1108/AAAJ-06-2014-1736

Denzin, N. K., \& Lincoln, Y. S. (2000). Introduction: The discipline and practice of qualitative research. In Denzin, N. K. and Lincoln, Y. S. (Eds.), Handbook of Qualitative Research. Sage Publications, Thousand Oaks, CA.

Dumay, J., \& Dai, T. M. X. (2014). Integrated thinking as an organisational cultural control? in Critical perspectives on accounting conference.

Dumay, J., Bernardi, C., Guthrie, J., \& Demartini, P. (2016). Integrated reporting: A structured literature review. Accounting Forum, 40(3), 166-185. https://doi.org/10.1016/j.accfor.2016.06.001

Eccles, R. G., \& Krzus, M. P. (2010). One Report: Integrated Reporting for a Sustainable Strategy. John Wiley $\&$ Sons, New York.

Eccles, R., \& Kiron, D. (2012). Get ready: Mandated Integrated Reporting is the future of corporate reporting. MIT Sloan Management Review, 53(3), 1-5.

EY. (2014). Integrated Reporting-Elevating value. EYGM Limited. Retrieved from http://www.ey.com/Publication/vwLUAssets/EY-Integrated-reporting/\$FILE/EY-Integrated-reporting.pdf

Feng F., Cummings L., \& Tweedie D. (2017). Exploring integrated thinking in integrated reporting-An exploratory study in Australia. Journal of Intellectual Capital, 18(2), 330-353. https://doi.org/10.1108/JIC-06-2016-0068 
Fifka, M. S. (2013). Corporate responsibility reporting and its determinants in comparative perspective-A review of the empirical literature and a meta-analysis. Business Strategy and the Environment, 22(1), 1-35. https://doi.org/10.1002/bse.729

Frostenson, M., Helin, S., \& Sandström, J. (2012). Sustainability reporting as negotiated storytelling. paper presented at EBEN Research Conference, 7-9 June 2012, Newcastle University Business School, Newcastle upon Tyne.

Gassmann, O., Frankenberger, K., \& Csik, M. (2014). The Business Model Navigator (1st ed.). Harlow, Pearson.

Haji, A. A., \& Anifowose, M. (2017). Initial trends in corporate disclosures following the introduction of integrated reporting practice in South Africa. Journal of Intellectual Capital, 18(2), 373-399. https://doi.org/10.1108/JIC-01-2016-0020

Hampton, R. (2012). Brace yourself: More regulatory changes. Accountancy SA, 14, 22-23.

Higgins, C., Stubbs, W., \& Love, T. (2014). Walking the talk(s): Organisational narratives of integrated reporting. $\begin{array}{llll}\text { Accounting, Auditing \& } \quad \text { Accountability Journal, 27(7), } & \text { 1090-1119. }\end{array}$ https://doi.org/10.1108/AAAJ-04-2013-1303

International Integrated Reporting Council (IIRC). (2013). The International $<\mathrm{IR}>$ Framework, International Integrated Reporting Council, London.

KPMG. (2012). Integrated Reporting - Performance insights through better business reporting. KPMG International, http://integratedreporting.org/wp-content/uploads/2012/06/KPMG-Integrated-Reporting-Performance-Insig ht-Through-Better-Business-Reporting-Issue-2.pdf

Kreiner, K., \& Mouritsen, J. (2005). The analytical interview. Relevance beyond reflexivity", in Tengblad, S., Solli, R. and Czarniawska, B. (Eds.), The Art of Science. Kristianstad, SW: Liber \& Copenhagen Business School Press.

Kvale, S., \& Brinkmann, S. (2009). Inter Views: Learning the Craft of Qualitative Research Interviewing. Los Angeles, CA: Sage Publications.

Lodhia, S. (2015). Exploring the transition to integrated reporting through a practice lens: An Australian customer owned bank perspective. Journal of Business Ethics, 129, 585-598. https://doi.org/10.1007/s10551-014-2194-8

McGrath, R. G. (2010). Business models: A discovery driven approach. Long Range Planning, 43(2), 247-61. http://doi.org/10.1016/j.lrp.2009.07.005

Mio, C., Fasan, M., \& Pauluzzo, R. (2016). Internal Application of IR Principles: Generali’s Internal Integrated Reporting. Journal of Cleaner Production, 139, 204-218. https://doi.org/10.1016/j.jclepro.2016.07.149

Montemari, M., \& Chiucchi, M. S. (2018). Enabling Intellectual Capital Measurement Through Business Model Mapping: The Nexus Case. In Guthrie, J., Dumay, J., Ricceri, F. and Nielsen, C. (Eds.), The Routledge Companion to Intellectual Capital (pp. 266-283). London: Routledge.

Nielsen, C., \& Montemari, M. (2012). The role of human resources in business model performance: The case of network-based companies. Journal of Human Resource Costing \& Accounting, 16(2), 142-64. http://doi.org/10.1108/1401338121128425

Osterwalder, A., \& Pigneur, Y. (2010). Business model generation. A handbook for visionaries, game changers and challengers. John Wiley and Sons, Hoboken.

Patton, M. Q. (1990). Qualitative Evaluation and Research Methods (2nd ed.). Beverly Hills, CA: Sage Publications.

Patton, M. Q. (2002). Qualitative Research and Evaluation Methods. Thousand Oaks, CA: Sage Publications.

Perego, P., Kennedy, S., \& Whiteman, G. (2016). A lot of icing but little cake? Taking integrated reporting forward. Journal of Cleaner Production, 136, 53-64. https://doi.org/10.1016/j.jclepro.2016.01.106

PWC (2015). Implementing Integrated Reporting-PwC's practical guide for a new business language. Price water house Coopers $\quad$ LLP. $\quad$ Retrieved rom http://www.pwc.com/gx/en/audit-services/publications/assets/pwc-ir-practical-guide.pdf

Ryan, B., Scapens, R. W., \& Theobald, M. (2002). Research Method and Methodology in Finance and Accounting. T London: Thomson Learning. 
Steyn, M. (2014). Organisational benefits and implementation challenges of mandatory integrated reporting. Sustainability Accounting, Management and Policy Journal, 5(4), 476-503. https://doi.org/10.1108/SAMPJ-11-2013-0052

Stubbs, W., \& Higgins, C. (2014). Integrating reporting and internal mechanisms of change. Accounting, Auditing \& Accountability Journal, 27(7), 1068-1089. https://doi.org/10.1108/AAAJ-03-2013-1279

Taran, Y., Nielsen, C., Montemari, M., Thomsen, P., \& Paolone, F. (2016). Business model configurations: A five-V framework to map out potential innovation routes. European Journal of Innovation Management, 19(4), 492-527. https://doi.org/10.1108/EJIM-10-2015-0099

Thomson I. (2015). But does sustainability need capitalism or an integrated report? A commentary on 'The International Integrated Reporting Council: A story of failure' by Flower J. Critical Perspectives on Accounting, 27, 18-22. https://doi.org/10.1016/j.cpa.2014.07.003

Van Bommel, K. (2014). Towards a legitimate compromise? An exploration of Integrated Reporting in the Netherlands. Accounting, Auditing and Accountability Journal, 27(7), 1157-1189. https://doi.org/10.1108/AAAJ-04-2013-1309

Watson, A. (2011). Financial information in an integrated report: A forward looking approach. Accountancy SA.

Yin, R. K. (2003). Case Study Research: Design and Methods (3rd ed.). Beverly Hills, CA: Sage Publications.

\section{Copyrights}

Copyright for this article is retained by the author(s), with first publication rights granted to the journal.

This is an open-access article distributed under the terms and conditions of the Creative Commons Attribution license (http://creativecommons.org/licenses/by/4.0/). 